\title{
Factors affecting outcomes in Crohn's disease over 15 years
}

\author{
Jacques Cosnes, Anne Bourrier, Isabelle Nion-Larmurier, Harry Sokol, \\ Laurent Beaugerie, Philippe Seksik
}

Gastroenterology \& Nutrition Unit St-Antoine Hospital and Pierre-et-Marie Curie University (PARIS VI), APHP, Paris, France

\section{Correspondence to}

Dr Professor Philippe Seksik, St-Antoine Hospital

Gastroenterology \& Nutrition Unit, 184 rue du Faubourg St-Antoine, 75571 Paris, France; philippe.seksik@sat.aphp.fr

Revised 25 January 2012 Accepted 26 January 2012 Published Online First 2 March 2012

This paper is freely available online under the BMJ Journals unlocked scheme, see http:// gut.bmj.com/site/about/ unlocked.xhtml

\section{INTRODUCTION}

Crohn's disease (CD) progression is marked by the occurrence of stricturing complications or intestinal and perianal penetrating complications, typically requiring surgery. ${ }^{12}$ We previously reported three factors at the time of diagnosis that increased the chance of disabling disease during the 5 years following: (1) age <40 years old, (2) presence of perianal lesions and (3) the requirement for steroids to control the first flare. ${ }^{3}$ However, as the median age of diagnosis is 27 years, the course of $\mathrm{CD}$ may last more than 50 years in the Western world, where the life expectancy of patients exceeds 70 years. Therefore, identifying predictive criteria throughout such a long period remains challenging. We believe the assessment of CD severity should not be skewed by only taking into account occasional disease events. ${ }^{4}$ For example, one patient may be operated on once and then experience a long period of quiescent disease. CD manifestations are often quite active during the early few years before subsequently resolving and becoming more stable. ${ }^{5}$ One may consider a CD complication as an acute phenomenon without recurrence, ${ }^{6}$ and, in the absence of significant sequelae, such an event should therefore not be regarded as a marker of severe disease. Notably, most therapeutic strategies aim to avoid short-term complications; however, $\mathrm{CD}$ is a chronic disease requiring lifelong monitoring. Very little is known about the long-term evolution of CD. Therefore, the aim of our study was to identify predictable factors associated with a mild-to-moderate, long-term CD course; for this purpose, we prospectively analysed a large cohort of patients with $\mathrm{CD}$ over 15 -year period.

\section{METHODS \\ Patients}

Patients with complete 15 -year follow-up records were selected from the MICISTA Registry. This tertiary clinical database of more than 7000 patients with inflammatory bowel disease (IBD) evaluated by the same staff of doctors at Rothschild hospital (1974 to 2002), then St-Antoine hospital (from 2003 through the present) in Paris (built in 1994). Data were collected prospectively. CD diagnosis was based on the criteria defined by Lennard-Jones. ${ }^{7}$ In March 2010 there were 4306 patients with a final diagnosis of $\mathrm{CD}$ in the registry. Among this population, 600 patients with CD were seen in our unit during 1995 and were followed through to December 2009, or death. They represent $67 \%$ of the total number (899) of patients with $\mathrm{CD}$ seen in our unit at that time.
Characteristics of the CD cohort at entry (1995)

Characteristics of patients were recorded in the MICISTA registry according to the medical charts before 1994 and prospectively from 1995 onwards. Disease location was assessed prior to inclusion in the study by the most recent small bowel images (x-ray) and endoscopic features. The extent of previous intestinal resections in each individual was codified using the Post-Surgical Handicap Index. The Post-Surgical Handicap Index has been developed to predict the functional consequences of intestinal resection for $\mathrm{CD}^{8}$ It is calculated from operative records, taking into account the location and extent of intestinal resection. An index score equal or superior to 20 has a high predictive value of diarrhoea following intestinal resection.

\section{Description of the CD evolution 1995 to 2009}

Disease activity was codified prospectively at each visit or hospitalisation for every calendar year according to a pre-established gradation from 0 to 5 (table 1). Disease activity was recorded during hospitalisation only when symptoms were clearly related to active $\mathrm{CD}$ and not treatment-related complications. Similarly, only intestinal surgery or proctological procedures performed for $\mathrm{CD}$ were taken into account and codified in the hospitalisation group. In addition, restorative procedures performed in a patient with inactive disease were not included in the grading. Finally, a stoma was considered permanent if associated to a proctectomy or still in place in 2009 after 5 years (consecutively).

\section{Classification of the severity of the 15 -year CD course}

In the absence of a well established classification system, a panel of 20 IBD experts from the 'Groupe d'Etudes Thérapeutiques des Affections Inflammatoires du tube Digestif' (GETAID) was interviewed to establish the most relevant criteria for discriminating a severe from a mild-to-moderate $C D$ course during a 15 -year period. The proposed criteria were the following: (1) number of years with active disease, (2) chronic, disabling extraintestinal manifestations, (3) number of intestinal surgeries, (4) disabling perianal disease, (5) number of perianal surgical procedures, (6) requirement for a temporary or permanent stoma and (7) death related, or not, to CD. Each expert codified items independently. A consensus emerged for classifying the evolution of CD as severe if during the 1995 to 2009 period one of the following criteria was met: (a) 
Table 1 Prospective codification of one individual in a calendar year

\begin{tabular}{ll}
\hline Activity and treatment & N \\
\hline Disease activity & 0 \\
Quiescent (no symptoms) & 1 \\
Minor symptoms without flare & 2 \\
Mild symptoms & 3 \\
Flare-up or chronic active disease & 4 \\
CD-related hospitalisation & 5 \\
Abdominal surgery for active CD or complication & \\
Maximal treatment received during the year & 0 \\
No treatment for CD & 1 \\
5-amino-salicylates or antibiotics for CD & 2 \\
Low dose steroids (<10 mg Prednisone per day) & 3 \\
Steroids & 4 \\
Immunosuppressants & 5 \\
Anti-TNF agents &
\end{tabular}

$C D$, Crohn's disease; TNF, tumour necrosis factor.

active disease (ie, grade $>1$ ), for more than 3 years consecutively or not; (b) more than one intestinal surgery; (c) establishment of a permanent stoma; (d) death related to CD or complications of $\mathrm{CD}$, or complications of $\mathrm{CD}$ treatment. The evolution was considered as mild-to-moderate in all other cases.

\section{Treatment}

Disease flares were treated with mesalamine ( $3-4 \mathrm{~g}$ daily) or steroids (prednisolone $1 \mathrm{mg} / \mathrm{kg}$ per day, or budesonide $9 \mathrm{mg}$ per day, each progressively tapered after 4 weeks), according to their clinical severity. When steroid treatment failed or was contraindicated, patients seen before 1999 were given enteral or parenteral nutrition; those seen after June 1999 received Infliximab. Adalimumab was used as a second-line anti-tumour necrosis factor (TNF) treatment after 2006. Metronidazole or ciprofloxacine were used in symptomatic perianal disease.

Patients with asymptomatic or moderately active forms of the disease were treated with aminosalicylates (1.6-3 g daily). Immunosuppressive drugs were used in patients that were steroid dependent or poorly responsive to steroids. Azathioprine $(2 \mathrm{mg} / \mathrm{kg}$ per day) was preferentially used as the immunosuppressive drug, and increased to $2.5-3 \mathrm{mg} / \mathrm{kg}$ per day if needed. Intramuscular methotrexate (15-25 mg, weekly) was used in patients unresponsive or intolerant to azathioprine. In cases of controlled CD, methotrexate was tapered after 3-6 months to $10-15 \mathrm{mg}$, weekly. In cases of poor responses to classical immunosuppressants, anti-TNF therapies were used for maintenance.

Although the overall strategy remained mostly unchanged, there was a distinct tendency to initiate immunosuppressants earlier in the disease course. ${ }^{9}$ Surgery was performed for stenotic complications, extraparietal complications, or intractable forms of $\mathrm{CD}$ after well conducted medical management.

The maximum treatment received by one patient during each calendar year was codified prospectively at each visit/hospitalisation, according to a pre-established gradation $(0-5$ (table 1$)$ ). All treatment(s) were taken into account, even in cases of short duration.

\section{Statistical analysis}

Statistical comparisons were performed using $\chi^{2}$, Fisher's exact, Student $t$ test or Wilcoxon test where appropriate. Identification of factors associated with mild-to-moderate, 15-year CD course was determined by using univariate and multivariate analyses. Most covariates were collected in 1995: age, gender, family history, educational level, obesity, disease duration, disease location according to Montreal classification (ie, at first surgery or in 1995 in patients who had not be operated upon), rectal involvement, perianal disease, systemic manifestations, prior intestinal stricture (Montreal classification), prior intestinal perforation (Montreal classification), prior perianal fistula, prior intestinal resection, prior immunosuppressive treatment and current immunosuppressive treatment. Three variables were collected at the end of the follow-up: (1) quality of follow-up care (how many visits per year), (2) any use of oral contraceptives during their lifetime and (3) active smoking during the 15 -year study. The smoking variable was qualified by more than one cigarette per day for at least 1 year. Statistically significant covariates $(\alpha=5 \%)$ in univariate analyses were included in a stepwise logistic regression (entering effect $=0.10$, removing $=0.05$ ). The goodness of fit for the final multivariate model was assessed with the Hosmer and Lemeshow test. The power of the model's predicted values to discriminate between severe and mild-to-moderate cases was quantified by the area under the receiver operating characteristic (ROC) curve (AUC). Statistical analyses were performed using SAS software V.9.1 (SAS, Cary, North Carolina, USA).

\section{RESULTS}

\section{Classification of the severity of the 15-year disease course}

The 15-year CD course was classified as mild-to-moderate in 279 of the 600 patients. Among them, all the patients experienced at least 12 years with no active disease, except six patients who died before 2010. Those six patients were classified as mild-tomoderate because four of them died after a period of 9-10 years of $\mathrm{CD}$ remission, and two of them died after only 1 year with active disease during the 10-12 previous years. A total of 61 patients $(22 \%)$ were operated on once during the 15 -year period for active or complicated $\mathrm{CD}$. The other 321 patients were classified in the severe $\mathrm{CD}$ group because of active disease for more than 3 years $(n=286)$, at least two abdominal operations for active or complicated $\mathrm{CD}(\mathrm{n}=58)$, the establishment of permanent stoma $(n=42)$, or death related to $C D(n=23)$. Tables 2-4 give the clinical characteristics of the two groups in 1995, at the end of follow-up and through the 15-year study, respectively.

\section{Year-by-year disease activity}

In the entire cohort of 600 patients, 6288 patient-years with inactive disease existed (grade $0-1 ; 72.2 \%$ ), 1641 patient-years with flare or chronic active disease not requiring hospitalisation existed (grade 2 or 3; 18.8\%), 453 patient-years with hospitalisation without abdominal surgery existed (grade $4 ; 5.2 \%$ ) and 344 patient-years with abdominal surgery existed (grade 5; 3.9\%).

Disease activity during the calendar years 1995 to 2009 in mild-to-moderate and severe $\mathrm{CD}$ is indicated in figure $1 \mathrm{~A}$. A significant trend towards lower disease activity is observed during the most recent years in severe and mild-to-moderate $\mathrm{CD}$ groups. When taking into account the entire cohort, the percentage of patients with active disease decreased linearly over the years from $43 \%$ to $14 \%(p<0.001)$. In the mild-to-moderate $\mathrm{CD}$ group, the proportion of patient-years with active disease was $14.8 \%, 6.7 \%$ and $5.6 \%$ during the periods 1995 to 1999,2000 to 2004 and 2005 to 2009 , respectively $(p<0.001)$. The proportion of patient-years with active disease in the severe $\mathrm{CD}$ group decreased from $60 \%$ (1995 to 1999) to $42 \%$ (2000 to 2004) and $32 \%(2005$ to 2009$)(\mathrm{p}<0.001)$.

In mild-to-moderate $\mathrm{CD}$ the percentage of patients with active disease each calendar year varied between $22.2 \%$ (1995) and 2.9\% (2007) (median, 9.3\% in 2001). Hospitalisation and 
Table 2 Characteristics of patients in the mild-to-moderate and severe Crohn's disease (CD) groups in 1995

\begin{tabular}{|c|c|c|c|c|}
\hline & All & $\begin{array}{l}\text { Mild-to-moderate } \\
\text { 15-year CD }\end{array}$ & Severe 15-year CD & p Value* \\
\hline $\mathrm{N}$ & 600 & 279 & 321 & \\
\hline Age, years & $32.6(26-42)$ & $36(28-46)$ & $31(24-39)$ & $<0.0001$ \\
\hline Female, \% & $356(59)$ & $158(57)$ & $198(62)$ & NS \\
\hline Disease duration, years & $5.9(2.3-10.0)$ & $9.4(3.9-15.2)$ & $5.4(2.1-10.3)$ & $<0.0001$ \\
\hline IBD family history, \% & $144(24)$ & $67(24)$ & $77(24)$ & NS \\
\hline Extradigestive manifestations, \% & $259(43)$ & $113(40)$ & $146(45)$ & NS \\
\hline \multicolumn{5}{|l|}{ Disease location, $\%$} \\
\hline $\mathrm{L} 1$ & $219(36)$ & $107(38)$ & $112(35)$ & \\
\hline L2 & $171(28)$ & $71(25)$ & $100(31)$ & NS \\
\hline L3 & $209(35)$ & $100(36)$ & $109(34)$ & \\
\hline Upper tract involvement (L4), \% & $62(10)$ & $28(10)$ & $53(17)$ & 0.02 \\
\hline Rectal involvement, \% & $229(38)$ & $90(32)$ & $139(43)$ & 0.006 \\
\hline Perianal lesions, \% & $258(43)$ & $122(44)$ & $136(42)$ & NS \\
\hline \multicolumn{5}{|l|}{ Disease behaviour, \% } \\
\hline B1 & $376(63)$ & $152(54)$ & $224(70)$ & 0.0001 \\
\hline B2 & $82(14)$ & $46(16)$ & $36(11)$ & \\
\hline B3 & $143(24)$ & $81(29)$ & $61(19)$ & \\
\hline Prior immunosuppressants, \% & $166(28)$ & $65(23)$ & $101(31)$ & $<0.0001$ \\
\hline Prior intestinal resection, \% & $265(44)$ & $152(54)$ & $113(35)$ & $<0.0001$ \\
\hline Permanent stoma, \% & $34(6)$ & $23(8)$ & $11(3)$ & 0.01 \\
\hline Post-Surgical Handicap Index & $20(0-34)$ & $9(0-25)$ & $0(0-18)$ & $<0.0001$ \\
\hline Obesity, \% & $115(19)$ & $57(20)$ & $58(18)$ & NS \\
\hline High educational level, \% & $235(39)$ & $126(45)$ & $109(34)$ & 0.005 \\
\hline
\end{tabular}

All quantitative data are given as median (IQR).

${ }^{*}$ Comparisons between mild-to-moderate and severe 15-year CD groups.

IBD, inflammatory bowel disease; NS, not significant.

surgery were required in few patients, and these events almost exclusively occurred during the early years of the study (1995 to 1999) (figure 1A). In severe CD the percentage of patients with active disease each calendar year varied between $67 \%$ (1995) and $25.1 \%$ (2007) (median, 43.2\% in 2002). The annual rate of hospitalisation, excluding abdominal surgery, varied from $13.4 \%$ (1996) to $2.7 \%$ (2007) (median, $7.3 \%$ in 2002) and the annual rate of abdominal surgery varied from $10.6 \%$ (1998) to $2 \%$ (2007) (median, 5.5\% in 2000) (figure 1A).

\section{Medical therapeutic requirements}

The number of patients with CD in the mild-to-moderate and severe groups who received 5-aminosalicylic acid (5-ASA), steroids, immunosuppressants and anti-TNF treatment as maximal treatment are indicated for each calendar year in figure 1B. In both groups a gradual increase in the use of immunosuppressants and anti-TNF treatment is observed over time. The proportion of patient-years in which immunosuppressants and/ or anti-TNF treatment were used in mild-to-moderate CD increased from $23.2 \%$ (1995 to 1999) to $26.4 \%$ (2000 to 2004) and finally to $27.8 \%$ (2005 to 2009) $(\mathrm{p}<0.001)$. In severe CD, these figures were $41.2 \%, 56.2 \%$ and $62.1 \%$, respectively

Table 3 Characteristics of the mild-to-moderate and severe Crohn's disease (CD) groups at the end of follow-up

\begin{tabular}{llll}
\hline & $\begin{array}{l}\text { Mild-to-moderate } \\
\text { 15-year CD }\end{array}$ & $\begin{array}{l}\text { Severe } \\
\text { 15-year CD }\end{array}$ & p Value \\
\hline $\mathrm{N}$ & 279 & 321 & \\
Deceased, \% & $6(2)$ & $29(9)$ & $\mathrm{NA}$ \\
Age & $49(42-59)$ & $45(38-52)$ & $<0.0001$ \\
Post-Surgical Handicap Index & $19(0-30)$ & $20(0-37)$ & 0.016 \\
Permanent stoma, \% & $23(8)$ & $53(17)$ & 0.002
\end{tabular}

All quantitative data are given as median (IQR).

NA, not applicable (item linked to the post hoc classification).
Table 4 Main events during the 15-year follow-up

\begin{tabular}{|c|c|c|c|}
\hline & $\begin{array}{l}\text { Mild-to-moderate } \\
\text { 15-year CD }\end{array}$ & $\begin{array}{l}\text { Severe } \\
15 \text {-year CD }\end{array}$ & p Value \\
\hline $\mathrm{N}$ & 279 & 321 & \\
\hline Close follow-up, \% & $187(67)$ & $208(65)$ & NS \\
\hline Ever use of oral contraceptives, \% & $54(49)^{*}$ & $82(61)^{*}$ & NS \\
\hline Any smoking, \% & $121(43)$ & $182(57)$ & 0.001 \\
\hline Death related to $C D, \%$ & 0 & $23(7)$ & NA \\
\hline Death unrelated to $C D, \%$ & $6(2)$ & $6(2)$ & NS \\
\hline Intestinal adenocarcinoma, \% & 1 & 18 & $<0.0001$ \\
\hline Lymphoma, \% & 1 & 1 & NS \\
\hline Other malignancies, $\%$ & 20 & 14 & NS \\
\hline \multicolumn{4}{|l|}{ No. of years with active disease } \\
\hline 0 & $89(32)$ & $4(1)$ & NA \\
\hline 1 & $62(22)$ & $6(2)$ & \\
\hline 2 & $69(25)$ & $11(3)$ & \\
\hline 3 & $59(21)$ & $17(5)$ & \\
\hline $4-5$ & 0 & $108(34)$ & \\
\hline $6-10$ & 0 & $134(42)$ & \\
\hline$>10$ & 0 & $41(13)$ & \\
\hline \multicolumn{4}{|l|}{ Changing behaviour, \% } \\
\hline $\mathrm{B} 1$ to $\mathrm{B} 2$ & $19(12)^{*}$ & $41(18)^{*}$ & $<0.001$ \\
\hline $\mathrm{B} 1$ to $\mathrm{B} 3$ & $18(12)^{*}$ & $56(25)^{*}$ & - \\
\hline $\mathrm{B} 2$ to $\mathrm{B} 3$ & $3(7)^{*}$ & $4(11)^{*}$ & NS \\
\hline Intestinal resection(s) & $61(22)$ & $189(59)$ & NA \\
\hline Delta PSHI & $0(0-0)$ & $7(0-21)$ & $<0.01$ \\
\hline Establishment of a permanent stoma & 0 & $42(14)^{*}$ & NA \\
\hline Proctological procedure(s) & $20(8)^{*}$ & $75(24)^{*}$ & $<0.0001$ \\
\hline
\end{tabular}


Figure 1 Year-by-year disease activity and maximal treatment from 1995 to 2009 in the two groups of patients with Crohn's disease (CD). (A) Year-by-year disease activity from 1995 to 2009. (B) Year-by-year maximal treatment from 1995 to 2009 in the two groups of patients with CD.
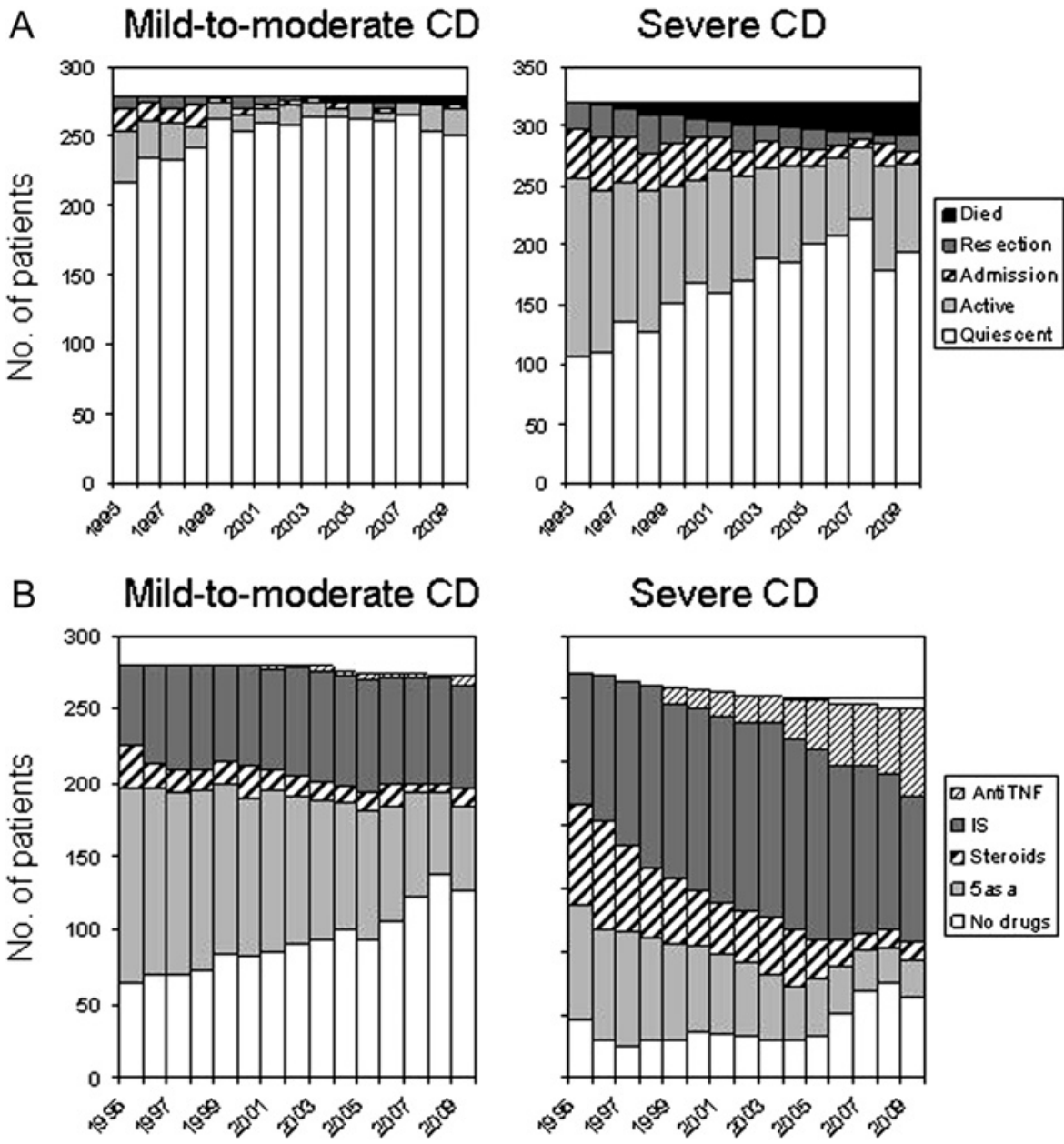

$(p<0.001)$. Trends in both groups exhibited a coincident decrease in 5-ASA and steroid usage as the maximal treatment over time. As the use of 5-ASA and steroids in association with immunosuppressants was not reported, the observed decrease in the proportion of patients taking 5-ASA or steroids cannot be interpreted. Finally, there was a significant increase in the percentage of patients receiving no medical treatment over time, notably in the most recent years. This trend was more marked in the mild-to-moderate CD group (from 25.9\% in 1995 to 1999 to $43 \%$ in 2005 to $2009, \mathrm{p}<0.001$ ) than in severe CD (from $10.2 \%$ in 1995 to 1999 to $19.9 \%$ in 2005 to $2009, \mathrm{p}<0.001$ ).

In total, throughout the 15 -year period, 116 patients with mild-to-moderate CD (41.6\%) eventually received immunosuppressants and 14 received anti-TNF treatment (5\%). In the severe CD cohort, 268 (83.5\%) patients received immunosuppressants and 97 (31.4\%), received anti-TNF treatment.
Factors associated with a mild-to-moderate disease course

Table 5 indicates the variables selected by univariate analysis which entered the multivariate model. After adjustment for confounding, significant factors associated with a mild-tomoderate 15-year disease course were the following: (1) nonsmoking, (2) higher educational level, (3) rectal sparing, (4) older age and (5) longer disease duration prior to inclusion. The model was a good fit to the data (Hosmer and Lemeshow: $p=0.51$ ). The area under the ROC curve was 0.69 . The probability of a mildto-moderate course was given by the following formula: $\operatorname{logit}(p)=-0.8715+0.0148 \times$ age (years) $+0.0479 \times$ disease duration (years) $-0.3992 \times$ ever smoking $(0$ or 1$)-0.4503 \times$ rectal involvement ( 0 or 1$)+0.3915 \times$ high educational level ( 0 or 1 ). This model demonstrates that a 15 -year time course increased the probability of having subsequent mild-to-moderate disease by $0.208 \pm 0.032$. This increased probability was similar when

Table 5 Variables associated with a mild-to-moderate Crohn's disease (CD) 15-year course selected by logistic regression

\begin{tabular}{lccccc}
\hline & \multicolumn{2}{l}{ Univariate analysis } & & \multicolumn{2}{l}{ Multivariate analysis } \\
\cline { 2 - 3 } & p Value & OR (Cl 95\%) & & p Value & OR (CI 95\%) \\
\hline Age & $<0.0001$ & $1.03(1.02$ to 1.04$)$ & & 0.041 & $1.01(1.00$ to 1.03$)$ \\
High educational level & 0.005 & $1.60(1.15$ to 2.23$)$ & & 0.026 & $1.48(1.05$ to 2.09$)$ \\
Ever smoking & 0.001 & $0.58(0.42$ to 0.81$)$ & & 0.022 & $0.67(0.48$ to 0.94$)$ \\
Disease duration & $<0.0001$ & $1.06(1.04$ to 1.09$)$ & & $<0.001$ & $1.05(1.02$ to 1.08$)$ \\
Rectal involvement & 0.006 & $0.62(0.45$ to 0.87$)$ & & 0.011 & $0.64(0.45$ to 0.90$)$ \\
Prior intestinal stricture & $<0.001$ & $2.09(1.39$ to 3.14$)$ & & NS & \\
Prior intestinal perforation & 0.002 & $1.86(1.26$ to 2.72$)$ & & NS & \\
Prior intestinal resection & $<0.0001$ & $2.20(1.59$ to 3.06$)$ & & NS & \\
\hline
\end{tabular}

NS, not significant. 
Table 6 Association of the selected variables with the criteria defining 15-year Crohn's disease (CD) severity

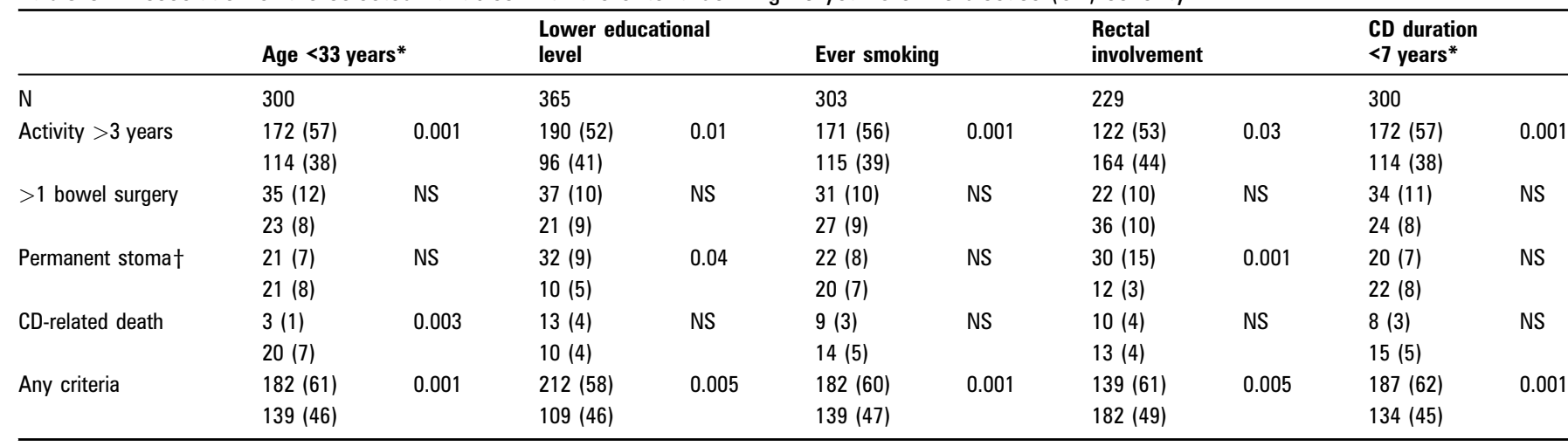

*Median value for the 600 patients.

†Patients with prior permanent stoma excluded.

NS, not significant.

analysing patients with mild-to-moderate $(0.201 \pm 0.039)$ and severe disease courses $(0.214 \pm 0.024)$.

Table 6 indicates the respective contribution of each selected variable to the different criteria used for defining CD severity. Neither CD-related death nor the surgical criteria (more than one abdominal surgery) were significantly associated with any selected variable. However CD activity was associated with the five selected variables, and the establishment of a permanent stoma was associated with rectal involvement and lower educational level.

\section{DISCUSSION}

The present study shows that long-term prognosis of CD is not related to anatomical characteristics of the disease, except for rectal involvement. Smoking and low educational level are associated with a more severe disease course. In addition, this study demonstrates that age and disease duration are associated with a less severe course.

To date, our study is unique in the literature with regard to the number of patients, the prospective collection of data and the management of the study by a small, consistent group of doctors. Compared to population-based studies, referral-based cohorts, such as our cohort, enrol younger patients with more fistulas, steroids and immunosuppressant use. ${ }^{10}$ This recruitment bias may lead to an overestimation of patients with severe disease but does not compromise the comparisons drawn between severe and mild-to-moderate CD. Thus, the proposed prognostic factors should be validated in independent population-based cohorts.

Disease location and behaviour had no impact on the overall severity of CD course throughout the 15-year study. It is well established that the risk of intestinal surgery in CD is increased in cases of previous intestinal complications, ${ }^{6} 1112$ especially when the small bowel is involved. ${ }^{13}{ }^{14}$ However the risk of surgery should not be regarded as a major issue when the overall prognosis is discerned. Different from colitis, ileal CD is characterised by a higher need for surgery, balanced by a lesser inflammatory activity, thus it is not surprising that the longterm prognosis is not different in these two conditions. The behaviour of our patients was classified according to the Montreal classification, which is based upon the cumulative complications rate. ${ }^{15}$ The absence of an effect on the cumulative behaviour at a given time on the subsequent evolution confirms its limited prognostic value. ${ }^{1}{ }^{2}$ Moreover, we did not observe that patients with perianal disease experience a more severe CD course. ${ }^{16}$ Our study highlighted rectal involvement has an effect on long-term prognosis and that this effect may be due to the association between rectal involvement and refractory perianal disease with the need for proctectomy (table 6). This result is in accordance with most data showing that rectal involvement is associated with a higher risk for permanent stomas in patients requiring surgery for perianal lesions. ${ }^{17} 18$

The long-term harmful effect of smoking in CD was once again confirmed in our cohort. Of note, smoking was associated with increased disease activity but not with a need for a second operation (table 6). ${ }^{19} 20$ The beneficial effect of a higher educational level was somewhat unexpected, particularly because, in France, level of education has no impact on access to health resources. ${ }^{21}$ However, educational level may inadvertently affect compliance $^{22}$ and, indeed, non-adherence has been reported in over onethird of patients taking maintenance therapies for inflammatory bowel disease which may negatively contribute to $\mathrm{CD}$ management. ${ }^{23} 24$ Better compliance may be achieved in patients with $\mathrm{CD}$ with a lower educational level through enrolment in a patient association. $^{21} 25$ Furthermore, a high educational level may be linked to a more cautious lifestyle behaviour and somehow protect patients with CD from environmental triggers.

Disease duration and age at inclusion in the study were both independent factors associated with a lesser severity of CD. The beneficial effect of time was not related to prior intestinal resection (table 5). We calculated from the logistic regression model that a 15-year lag time decreased the probability of having a subsequent severe course by approximately $20 \%$. To our knowledge this is the first study demonstrating that, time is an independent factor for lower CD disease activity. The IBSEN study ${ }^{12}$ demonstrated a greater likelihood of prolonged remission was associated with patients over 40 years of age. However, the landmark study by Munkholm et al showed that the initial 3 years following diagnosis are the most active and should be considered separately for these analyses. In the latter study, a remarkably constant percentage of patients (55\%) were classified in clinical remission each year after the initial 3 years after diagnosis. ${ }^{5}$ However, more than 15 years after diagnosis, there was a higher proportion of patients changing from active to remission status than vice versa each year. ${ }^{5}$ In addition, our study shows, through year-by-year analysis of CD activity, the positive effect of disease duration and was more marked during the more recent years (figure 1A). When analysing our cohort excluding patients with $<3$ years of disease evolution before entering the cohort $(n=159)$, we found similar results (data not shown). In mild-to-moderate $\mathrm{CD}$, percentage of patients with active disease decreased over the years and a large cohort of patients was 
relieved of treatment while no de-escalation protocol was currently followed. Similarly, in severe CD cases, there was also a higher proportion of patients without any treatment. The proportion of patients under immunosuppressants (comprising steroids and anti-TNF) did not change over years. Thus, it is probable that the decrease in disease activity observed over the years in the study was poorly related to the treatment regimen, but was the consequence of a natural waning of disease. Taken together these data support the conclusion that overall CD activity declines over time, albeit in a limited magnitude.

Finally, long-term evolution of CD is weakly predictable. New approaches using biomarkers to predict disease course are needed. ${ }^{26} 27$ Moreover, about one-half of the patients from a referral centre will have a mild-to-moderate, long-term evolution and this proportion should be kept in mind when considering treatment strategies. In addition, among factors associated with a severe evolution of $\mathrm{CD}$, smoking remains the most challenging factor for patients to overcome. Lastly, rectal disease should receive major attention in order to decrease permanent stoma, and, moreover, efforts should be attempted to better understand $\mathrm{CD}$ progression.

Acknowledgements We express our gratitude to all doctors of Rothschild and StAntoine hospitals who were involved in the care of patients included in this study, in alphabetic order: Pauline Afchain, Philippe Baumer, Jérôme Bellanger, Antoine Blain, Franck Carbonnel, Stéphane Cattan, Jean-François Contou, Hélène d'Almagne, Daniel Evard, Jean-Pierre Gendre, Philippe Lamy, Yves Le Quintrec, Yann Ngo, Didier Reijasse, Virgine Sebbagh, Ariane Vienne.

Contributors JC, HS and PS wrote the manuscript. All the authors were involved in data management and critical revision of the manuscript.

Funding This work was supported by a research grant support from Abbott. The MICISTA database was adapted to the internet with funding from Association François Aupetit.

Disclosures JC received consulting fees from Abbott, LB received consulting fees from Abbott, PS received consulting fees from Ferring and Biocodex, The remaining authors state they have no conflicts.

Competing interests None.

Patient consent Obtained.

Ethics approval CNIL (Commission Nationale) n 1104603.

Provenance and peer review Not commissioned; externally peer reviewed.

Data sharing statement $\mathrm{JC}$ had the leadership in study design and had full access to all of the data in the study. He takes responsibility for the integrity of the data and the accuracy of the data analysis. The statistical analysis of the entire data set was performed by two independent biostatisticians, Flavien Roux and Frederic Mistretta (RCTs, Lyon, France).

\section{REFERENCES}

1. Cosnes J, Cattan S, Blain A, et al. Long-term evolution of disease behavior of Crohn's disease. Inflamm Bowel Dis 2002;8:244-50.

2. Louis $\mathbf{E}$, Collard A, Oger AF, et al. Behaviour of Crohn's disease according to the Vienna classification: changing pattern over the course of the disease. Gut 2001:49:777-82.
3. Beaugerie L, Seksik P, Nion-Larmurier I, et al. Predictors of Crohn's disease. Gastroenterology 2006;130:650-6.

4. Silverstein MD, Loftus EV, Sandborn WJ, et al. Clinical course and costs of care for Crohn's disease: Markov model analysis of a population-based cohort. Gastroenterology 1999;117:49-57.

5. Munkholm P, Langholz E, Davidsen $\mathrm{M}$, et al. Disease activity courses in a regional cohort of Crohn's disease patients. Scand J Gastroenterol 1995;30:699-706.

6. Greenstein AJ, Lachman P, Sachar DB, et al. Perforating and non-perforating indications for repeated operations in Crohn's disease: evidence for two clinical forms. Gut 1988;29:588-92

7. Lennard-Jones J. Classification of inflammatory bowel disease. Scand J Gastroenterol 1989;24:2-6.

8. Cosnes J, de Parades V, Carbonnel F, et al. Classification of the sequelae of bowe resection for Crohn's disease. Br J Surg 1994;81:1627-31.

9. Cosnes J, Nion-Larmurier I, Beaugerie L, et al. Impact of the increasing use of immunosuppressants in Crohn's disease on the need for intestinal surgery. Gut 2005:54:237-41.

10. Zankel E, Rogler G, Andus T, et al. Crohn's disease patient characteristics in a tertiary referral center: comparison with patients from a population-based cohort. Eur J Gastroenterol Hepatol 2005:17:395-401.

11. Brihier $\mathbf{H}$, Nion-Larmurier I, Afchain P, et al. Intestinal perforation in Crohn's disease Factors predictive of surgical resection. Gastroenterol Clin Biol 2005;29:1105-11.

12. Solberg IC, Vatn MH, Hoie 0, et al; IBSEN Study Group. Clinical course in Crohn's disease: results of a Norwegian population-based ten-year follow-up study. Clin Gastroenterol Hepatol 2007:5:1430-8.

13. Sands BE, Arsenault JE, Rosen MJ, et al. Risk of early surgery for Crohn's disease: implications for early treatment strategies. Am J Gastroenterol 2003;98:2712-18.

14. Bernell 0, Lapidus A, Hellers G. Risk factors for surgery and postoperative recurrence in Crohn's disease. Ann Surg 2000;231:38-45.

15. Silverberg M, Satsangi J, Ahmad T, et al. Toward an integrated clinical, molecula and serological classification of inflammatory bowel disease: report of a working party of the 2005 Montreal world congress of gastroenterology. Can J Gastroenterol 2005:19:1A-32A.

16. Vermeire S, Van Assche G, Rutgeerts P. Perianal Crohn's disease: classification and clinical evaluation. Dig Liver Dis 2007;39:959-62.

17. Hurst RD, Molinari M, Chung TP, et al. Prospective study of the features, indications, and surgical treatment in 513 consecutive patients affected by Crohn's disease. Surgery 1997;122:661-7; discussion 667-8.

18. Regimbeau JM, Panis Y, Marteau P, et al. Surgical treatment of anoperineal Crohn's disease: can abdominoperineal resection be predicted? J Am Coll Surg 1999:189:171-6.

19. Yamamoto T, Keighley MR. Smoking and disease recurrence after operation for Crohn's disease. Br J Surg 2000;87:398-404.

20. Ryan WR, Allan RN, Yamamoto T, et al. Crohn's disease patients who quit smoking have a reduced risk of reoperation for recurrence. Am J Surg 2004;187:219-25.

21. Nahon S, Lahmek P, Macaigne G, et al. Socioeconomic deprivation does not influence the severity of Crohn's disease: results of a prospective multicenter study. Inflamm Bowel Dis 2009;15:594-8.

22. Subasinghe $\mathbf{D}$, Wijekoon NS, Nawarathne NM, et al. Disease-related knowledge in inflammatory bowel disease: experience of a tertiary care centre in a developing country in South Asia. Singapore Med J 2010;51:484-9.

23. Horne R, Parham R, Driscoll R, et al. Patients' attitudes to medicines and adherence to maintenance treatment in inflammatory bowel disease. Inflamm Bowel Dis 2009;15:837-44

24. Bernal I, Domenech E, Garcia-Planella E, et al. Medication-taking behavior in a cohort of patients with inflammatory bowel disease. Dig Dis Sci 2006:51:2165-9.

25. Nahon S, Lahmek P, Saas C, et al. Socioeconomic and psychological factors associated with nonadherence to treatment in inflammatory bowel disease patients: results of the ISSE0 survey. Inflamm Bowel Dis 2011:17:1270-6.

26. Lichtenstein GR, Targan SR, Dubinsky MC, et al. Combination of genetic and quantitative serological immune markers are associated with complicated Crohn's disease behavior. Inflamm Bowel Dis 2011;17:2488-96.

27. Dubinsky MC, Kugathasan S, Mei L, et al. Increased immune reactivity predicts aggressive complicating Crohn's disease in children. Clin Gastroenterol Hepatol 2008;6:1105-11

The term "pegylated interferon-N1 plus ribavirin" in the abstract should read "pegylated interferon- $\alpha$ plus ribavirin". 